\title{
In Vitro Comparison of, Accuracy of Raypex 5 and Root ZXII Apex Locators, for Working Length Determination in Primary Teeth
}

\author{
Shahram Mosharafian ${ }^{1}$, Najmeh Mollaie², Maryam Azizi Shoul ${ }^{3}$, Marzieh Salehi Shahrabi ${ }^{4}$ \\ ${ }^{1}$ Department of Paediatric Dentistry, Tehran University of Medical Sciences, Tehran, Iran. ${ }^{2}$ Department of \\ Orthodontics, Faculty of Dentistry, Rafsanjan University of Medical Sciences, Rafsanjan, Iran. ${ }^{3}$ Department of \\ Operative Dentistry, Faculty of Dentistry, Rafsanjan University of Medical Sciences, Rafsanjan, Iran. \\ ${ }^{4}$ Department of Paediatric Dentistry, Tehran University of Medical Sciences, Tehran, Iran.
}

\section{ABSTRACT}

\section{BACKGROUND}

Working length determination is a fundamental step in the endodontic treatment of primary and permanent teeth. Radiography is most commonly used for this purpose. However, it requires patient cooperation and is associated with adverse effects of radiation. Apex locators can serve as an efficient alternative for this purpose. We wanted to compare the accuracy of Root ZXII and Raypex 5 electronic apex locators for working length determination in primary teeth.

\section{METHODS}

This in vitro study was performed on 154 canals of 58 extracted primary teeth. Access cavity was prepared, and a K-file was introduced into the canal until its tip was visible at the apex under a microscope. $0.5 \mathrm{~mm}$ was subtracted from this length to determine the actual working length. The canal length was then measured again using Root ZXII and Raypex 5 apex locators. The obtained values were compared with the actual value. Data was analysed using SPSS version 21 via paired t-test with intraclass correlation coefficient (ICC) at $\mathrm{P}<0.05$ level of significance.

\section{RESULTS}

The mean difference in values measured by Root ZXII and Raypex 5 and the actual working length was $0.77 \pm 0.65 \mathrm{~mm}$ and $0.62 \pm 0.58 \mathrm{~mm}$, respectively. No significant difference existed in the accuracy of the two apex locators for determination of actual working length $(\mathrm{P}=0.54)$. The actual working length had a strong correlation with the values measured by Root ZXII (ICC=0.97) and Raypex $5($ ICC=0.95).

\section{CONCLUSIONS}

Both apex locators have acceptable accuracy as an alternative to radiography for working length determination in primary teeth.

\section{KEY WORDS}

Electronic Apex Locator, Raypex 5, Root ZXII, Primary Teeth
Corresponding Author:

Marzieh Salehi Shahrabi,

Department of Pediatric Dentistry,

Tehran University of Medical Sciences,

Tehran, Iran.

E-mail: salehipegah7@gmail.com

DOI: $10.14260 / \mathrm{jemds} / 2020 / 348$

Financial or Other Competing Interests: None.

How to Cite This Article:

Mosharafian S, Mollaie N, Shoul MA, et al. In vitro comparison of, accuracy of raypex 5 and root ZXII apex locators, for working length determination in primary teeth. J. Evolution Med. Dent. Sci. 2020;9(20): 1594-1598, DOI:
Submission 16-03-2020,

Peer Review 30-04-2020,

Acceptance 06-05-2020,

Published 18-05-2020. 


\section{BACKGROUND}

Preservation of primary teeth is the main priority of paediatric dentists. ${ }^{(1,2)}$ However, preservation of primary teeth with inflamed or infected pulp tissue necessitates their endodontic treatment.(3) Accurate working length determination in primary teeth requiring pulpectomy is a critical step for a successful endodontic treatment and also to ensure no trauma to the permanent successor tooth bud and resolve periapical inflammation.(4-6)

Radiography is the technique of choice for working length determination. However, accurate determination of the location of root apices on radiographs may be difficult due to the complex anatomy of the root canal system of primary teeth, root superimposition and poor cooperation of paediatric patients. (7-9) Root canal preparation is highly affected by the root canal anatomy,(10) and radiography may fail to accurately unveil the complex anatomy of the canal in some cases. This is particularly important in children since radiation exposure should be minimized in them. Moreover, radiographic interpretation of primary teeth with physiologic resorption of their buccal and lingual surfaces is difficult. Such shortcomings may increase the risk of overinstrumentation or over-filling, which, in primary teeth, can damage the tooth bud of the permanent successors. (8) On the other hand, under-filling can cause constant pain and discomfort due to the residual inflamed pulp tissue.(10,11)

Electronic apex locators are commonly used by clinicians considering their advantages such as eliminating the need for radiography or decreasing the number of required radiographs, optimal accuracy and ease of use. (3) Suzuki was the first to primarily design and produce apex locators in 1942.(10) In his study on dogs, he found that the electrical resistance between the periodontal membrane and oral mucosa is a constant value. This finding led to the advent of apex locators by Sunadain 1962 and its subsequent application in endodontics. Clinicians have been using apex locators for working length determination for over 40 years now.(10) Since the advent of apex locators, many studies have evaluated the efficacy of different generations of apex locators. A systematic review in 2014 reviewed studies on the accuracy of different apex locators and reported that of 38 studies reviewed, 16 found significant differences in the accuracy of different apex locators while others did not find any significant difference among different tested devices. (12)

Rootzx (J. moritacorp., Tokyo, Japan) is an example of third generation of electronic apex locators which is the gold standard evaluating other devices. Beside, Raypex®6 (VDW, Munich, Germany) is a multi-frequency apex locator and is comparable with third generation devices like Rootzx. One its advantages is the ability of automatic calibration. (13)

The apical foramen of primary teeth is often undifferentiated and/or large, which complicates canal length determination. However, some studies have confirmed the accuracy of apex locators for canal length determination in primary teeth. ${ }^{(1,2,10)}$ Studies on primary teeth show that apex locators are safe, painless and accurate. They are particularly efficient for use in pediatric patients to eliminate the risks of unnecessary radiation exposure in them.(2,9) However, studies on the accuracy of apex locators in primary teeth report a wide range of accuracy for them.(14) So since there was no study comparing the accuracy of Rootzx and Raypex2, the purpose of this study was to evaluate this common apex locators. The null hypothesis is that both two devices have acceptable results in primary teeth.

\section{METHODS}

This in observation study was carried out on 154 canals of 58 extracted primary teeth (20 anterior and 38 posterior teeth). The study protocol was approved by the regional committee for medical research ethics. The sample size was determined due to Kuştarci, A., et al study and following formula(15)

$\mathrm{N} 1=\mathrm{N} 2=\frac{\mathrm{P} 1(100-\mathrm{P} 1)+\mathrm{P} 2(100-\mathrm{P} 2)(\mathrm{Z} 1-\alpha / 2+\mathrm{Z} 1-\beta)}{(\mathrm{P} 1-\mathrm{P} 2)^{2}}$

P1 $=96.7 \%$ Denta Port ZX Percent accuracy within $\pm 0.5 \mathrm{~mm}$

P2 $=86.7 \%$ Endo Master ZX Percent accuracy within $\pm 0.5 \mathrm{~mm}$ Sample size based on the above formula with $\alpha=0.05$ and $d=$ 0.90

$\mathrm{N} 1=\mathrm{N} 2=\frac{=53(100-53)+10(100-10)(1.96+1.28)^{2}}{(53-10)^{2}}=154$

The teeth had been extracted for reasons such as orthodontic treatment or untreatable teeth because of deep crown caries or severe infection. The teeth did not have internal resorption or furcation involvement and their apical resorption did not exceed one-third of the root length. The collected teeth were immersed in $2.5 \%$ sodium hypochlorite solution for 3 hours for elimination of tissue residues and were then stored in saline until the experiment. Carious lesions were removed using a \#2 round bur with low-speed hand-piece (NSK, Japan). After access cavity preparation, the canals were negotiated and rinsed with saline. To find a fixed and reliable reference point, the incisal and occlusal edges of the teeth were gently ground with disc in order to create a smooth and wide surface. All teeth were coded and stored in containers.

Next, the actual canal length of each tooth was measured. For this purpose, a \#10 or $15 \mathrm{~K}$-file was introduced into the root canal until its tip was visible at the apex under a stereomicroscope (MBC-2, Russia) at x 12.5 magnification. The file was then removed from the canal and the distance between the rubber stop and file tip was measured using an endodontic ruler with $0.1 \mathrm{~mm}$ accuracy; $0.5 \mathrm{~mm}$ was subtracted from this length and the obtained value was recorded as the working length of the respective tooth.

Prior to the measurement of canal length with apex locators, an alginate model proposed by Kaufman and Katz (15) was used to simulate the periodontal ligament, which is accurate, stable, easy to use and affordable. The alginate model had to remain hydrated during the study period. The alginate powder (Iralgin, Iran) was mixed with water according to the manufacturer's instructions and poured into an amalgam well. Tooth roots were embedded in it to the level of their cervical region and fixed. (10)

Working length was then measured using Root ZXII O Morita Co., Kyoto, Japan) and Raypex 5 (VDW, Munich, Germany) apex locators according to their manufacturers' instructions. For measurement of canal length, the file clip 
was connected to the file and the lip clip was placed in the alginate before its complete setting. The canals were dried with paper points. The file was gently introduced into the canal and proceeded towards the apex until the display demonstrated the apical constriction or $0.5 \mathrm{~mm}$ distance to the canal opening. At this time, the rubber stop was adjusted to the coronal reference point and the file was removed from the canal. This was repeated for all canals. The distance between the rubber stop and file tip was measured by an endodontic ruler with $0.1 \mathrm{~mm}$ accuracy.

Data were analyzed using SPSS version 21 (SPSS Inc., IL, USA) via paired t-test and intraclass correlation coefficient (ICC). Level of significance was set at 0.05 .

\section{RESULTS}

The results of this study on 154 canals showed that the difference in the accuracy of the two apex locators was not significant $(\mathrm{P}=0.54$, table 1$)$. Table 2 indicates the difference in the measured working length by the two apex locators and the actual working length. As shown in Table 2, in $60.4 \%$ of the cases, the difference between the value measured by Root ZXII and the actual value was in the range of -0.5 to +0.5 . This value was between -1 and +1 in $81.8 \%$ of the cases. For the Raypex 5, this difference was between -0.5 to +0.5 in $58.5 \%$ and -1 and +1 in $81.2 \%$ of the cases. In other words, Raypex 5 and Root ZXII over-estimated the working length in $18.8 \%$ and $16.9 \%$ of the cases, respectively (table 2 ).

\begin{tabular}{|cccc|}
\hline Apex Locator & Mean & Standard Deviation & P Value \\
Raypex 5 & 0.62 & 0.58 & 0.54 \\
Root ZXII & 0.65 & 0.77 & \\
\hline Table 1. Difference of the Measured Length by Apex Locators \\
and the Actual Working Length (n=154) \\
\hline \multicolumn{4}{|c|}{} \\
\hline
\end{tabular}

\begin{tabular}{|ccc|}
\hline $\begin{array}{c}\text { Frequency (\%) } \\
\text { Raypex 5 }\end{array}$ & $\begin{array}{c}\text { Frequency (\%) } \\
\text { Root ZXII }\end{array}$ & $\begin{array}{c}\text { Difference with the actual } \\
\text { working length (mm) }\end{array}$ \\
$15(9.7)$ & $16(10.4)$ & $>1$ \\
$14(9.1)$ & $10(6.5)$ & 0.5 to 1 \\
$37(24.0)$ & $33(21.4)$ & 0 to 0.5 \\
$7(4.5)$ & $12(7.8)$ & 0 \\
$46(30.0)$ & $48(31.2)$ & -0.5 to 0 \\
$21(13.6)$ & $22(14.9)$ & -0.51 to -1 \\
$14(9.1)$ & $12(7.8)$ & $<-1$ \\
\hline Table 2. Frequency Distribution and Percentage of Measured Values \\
\hline
\end{tabular}

\begin{tabular}{|c|c|c|c|c|c|}
\hline Canal & $\begin{array}{c}\text { Apex } \\
\text { Locator }\end{array}$ & $\begin{array}{c}\text { Canal } \\
\text { Number }\end{array}$ & $\begin{array}{l}\text { Mean Difference } \\
\text { with Actual Value }\end{array}$ & $\begin{array}{l}\text { Standard } \\
\text { Deviation }\end{array}$ & $\begin{array}{c}P \\
\text { Value }\end{array}$ \\
\hline \multirow{2}{*}{ Mesiobuccal } & Raypex 5 & 39 & 0.54 & 0.53 & \multirow{2}{*}{0.63} \\
\hline & Root ZXII & 39 & 0.49 & 0.62 & \\
\hline \multirow{2}{*}{ Distobuccal } & Raypex 5 & 35 & 0.57 & 0.57 & \multirow{2}{*}{0.09} \\
\hline & Root ZXII & 35 & 0.80 & 0.98 & \\
\hline \multirow{2}{*}{ Mesiolingual } & Raypex 5 & 22 & 0.79 & 0.55 & \multirow{2}{*}{0.75} \\
\hline & Root ZXII & 22 & 0.73 & 1.0 & \\
\hline \multirow{2}{*}{ Distolingual } & Raypex 5 & 22 & 0.64 & 0.45 & \multirow{2}{*}{0.78} \\
\hline & Root ZXII & 22 & 0.61 & 0.59 & \\
\hline \multirow{2}{*}{ Palatal } & Raypex 5 & 16 & 0.75 & 1.0 & \multirow{2}{*}{0.94} \\
\hline & Root ZXII & 16 & 0.75 & 0.74 & \\
\hline \multirow{2}{*}{ Single canal } & Raypex 5 & 20 & 0.51 & 0.33 & \multirow{2}{*}{0.76} \\
\hline & Root ZXII & 20 & 0.54 & 0.41 & \\
\hline
\end{tabular}

Comparison of actual working length with the values measured by Root ZXII (ICC=0.95) and Raypex 5 (ICC=0.97) indicated a strong correlation. The absolute difference was used to calculate the mean and standard deviation. Positive values indicated over-estimation (exceeding the actual working length) and negative values indicated under- estimation (values shorter than the working length) of the working length. Zero indicated equal value with the actual working length. No significant difference was noted in the accuracy of working length determination by the two apex locators between single-rooted and multi-rooted teeth or different canal types including distobuccal, distolingual, mesiobuccal, mesiolingual and palatal (table 3). The absolute difference was used to calculate the mean and standard deviation.

\section{DISCUSSION}

Correct determination of actual working length is fundamental for successful endodontic treatment and preservation of primary teeth until their physiologic resorption.(16) Apex locators are accurate, safe and simple tools for working length determination especially in primary teeth. $(2,9,14)$ Although apex locators were introduced in 1962, their first and second generations were not accurate enough in presence of blood, pus or pulpal tissue. However, newer generations yielded more reliable results in such conditions. (13) In the present study, a strong correlation existed between the actual working length and the values measured by Root ZXII (ICC=0.95) and Raypex 5 (ICC=0.97), which confirmed their accuracy for working length determination irrespective of the type of tooth (single-rooted or multi-rooted) and presence/absence of resorption. This finding supported those of Leonardo et al. (10) They also reported a high correlation between the values reported by Root ZX and Mini-Apex and the actual canal length (ICC $=+0.99$ ). They concluded that the two tested apex locators are reliable and highly accurate for working length determination in primary teeth.(10)

As mentioned earlier, electronic apex locators are increasingly used by dental clinicians, and newer generations of them with higher accuracy are constantly introduced into the market. The manufacturers claim that their products are highly accurate and have an optimal performance. (3) The present study compared the accuracy of Root ZXII and Raypex 5 apex locators. Raypex 5 is a $4^{\text {th }}$ generation apex locator. A clinical study recommended its application for working length determination in primary teeth. However, to the best of authors' knowledge, no previous study has compared the accuracy of Raypex 5 with other apex locators. $^{(4)}$ Root ZXII is a $3^{\text {rd }}$ generation apex locator first developed in 1994. Its accuracy has also been confirmed in previous studies. $(1,17)$

In the current study, the difference between the length measured by Root ZXII and the actual canal length was between -1 to +1 in $81.8 \%$ of the cases; this value was $81.2 \%$ in use of Raypex 5. This finding was in agreement with those of Dandempally et al. (17) In their study, $87.33 \%$ of the measurements made with Root ZX were within the range of 0 $\pm 1 \mathrm{~mm}$ from the radiographic apex. However, the values obtained in our study were smaller than those reported by Khoshbin et al, who showed that $100 \%$ of the measurements made with Raypex 5 were within 0 to $-1 \mathrm{~mm}$ range from the radiographic apex.(3) In our study, however, the difference between the actual working length and the values measured 
by Root ZXII was between -0.5 to $+0.5 \mathrm{~mm}$ in $60.4 \%$ of the cases. This value was $58.4 \%$ for the Raypex 5 . In the study by Khoshbin et al,(3) values measured by Raypex 5 had 0 to -0.5 $\mathrm{mm}$ difference with the actual canal length in $81.2 \%$ of the cases, which was higher than the value obtained in our study. Our obtained values were also much lower than those of Kielbassa et al,(18) who measured the accuracy of Root ZXII to be 0.98 . Controversy in the results of studies may be due to different methodologies, differences in sample size and apex locator devices, type of teeth and study design (in vitro or in vivo). Nonetheless, it should be noted that the apical region of primary root canals may not be accurately identified due to root resorption. Thus, most researchers believe that -1 to +1 $\mathrm{mm}$ error range is acceptable in use of apex locators for primary teeth, $(2,14,17,18)$ although, according to some others, the acceptable range of error is -0.5 to +0.5 .(1) Therefore, considering the fact that apex locators have an accuracy of $70 \%$ to $95.8 \%$ in primary teeth, $(14,17,19)$ the values obtained in our study appear to be clinically acceptable. Thus, although radiography is the first choice for working length determination, evidence shows that apex locators are also reliable for this purpose and can bring about a successful treatment even in cases of root resorption. $(14,17,20)$

In the present study, the accuracy of the two tested apex locators (root ZXII and raypex 5) was not significantly different. Thus, they both can be used for accurate working length determination with -1 to $+1 \mathrm{~mm}$ error range (considering the high correlation of the measured values and the actual working length). However, these findings do not implicate that apex locators should replace radiography for working length determination. They can be used as a valuable adjunct to radiography and may decrease the number of required radiographs. (21) Radiographic assessment following working length determination by an apex locator can reveal the canal path and its anatomical details relative to the inserted file. (22)

In vitro design was a limitation of this study since problems that may occur during working length determination in the oral cavity and clinical setting are not encountered in vitro.

\section{CONCLUSIONS}

Results showed that both apex locators tested in this study had comparable and acceptable accuracy for working length determination of primary root canals. Use of apex locators is beneficial for working length determination in primary teeth due to their safety and ease of use.

\section{ACKNOWLEDGEMENT}

Authors thank the the faculty members of Paediatric Dentistry Department, and the Research Deputy of School of Dentistry, Tehran University of Medical Sciences.

\section{REFERENCES}

[1] Angwaravong 0, Panitvisai P. Accuracy of an electronic apex locator in primary teeth with root resorption. Int Endod J 2009;42(2):115-21.

[2] Bodur $\mathrm{H}$, Odabaş $\mathrm{M}$, Tulunoğlu 0 , et al. Accuracy of 2 different apex locators in primary teeth with and without root resorption. Clin Oral Investig 2008;12(2):137-41.

[3] Khoshbin E, Masoum T, Jalalzadeh SM. Clinical evaluation of the accuracy of Raypex5 electronic apex locator on root canal length determination in primary teeth. J Mash Dent Sch 2012;35(4):263-70.

[4] Bernardes RA, Duarte MAH, Vasconcelos BC, et al. Evaluation of precision of length determination with 3 electronic apex locators: Root ZX, Elements Diagnostic Unit and Apex Locator and Romi Apex D-30. Oral Surg Oral Med Oral Pathol Oral Radiol Endod 2007;104(4):e91-e4.

[5] D’Assunção FL, Albuquerque DS, Salazar-Silva JR, et al. The accuracy of root canal measurements using the Mini Apex Locator and Root ZX II: an evaluation in vitro. Oral Surg Oral Med Oral Pathol Oral Radiol Endod 2007;104(3):e50-3.

[6] Plotino G, Grande NM, Brigante L, et al. Ex vivo accuracy of three electronic apex locators: root ZX, elements diagnostic unit and apex locator and propex. Int Endod J 2006;39(5):408-14.

[7] Lozano A, Forner L, Liena C. In vitro comparison of root canal measurements with conventional and digital radiology. Int Endod J 2002;35(6):542-50.

[8] Mente J, Seidel J, Buchalla W, et al. Electronic determination of root canal length in primary teeth with and without root resorption. Int Endod J 2002;35(5):447-52.

[9] Krajczar K, Marada G, Gyulai G, et al. Comparison of radiographic and electronical working length determination on palatal and mesio-buccal root canals of extracted upper molars. Oral Surg Oral Med Oral Pathol Oral Radiol Endod 2008;106(2):e90-3.

[10] Leonardo MR, Silva LAB, Nelson-Filho P, et al. Ex vivo evaluation of the Ex vivo evaluation of the accuracy of two electronic apex locators during root canal length determination in primary teeth. Int Endod J 2008;41(4):317-21.

[11] Stober EK, Duran-Sindreu F, Mercade M, et al. An evaluation of Root ZX and IPEX apex locators: an in vivo study. J Endod 2011;37(5):608-10.

[12] Mosleh H, Khazaeil S, Razavian H, et al. Electronic apex locator: a comprehensive literature review - Part I. Different generations, comparison with other techniques and different usages. Dental Hypotheses 2014;5(3):8497.

[13] Samadi Y, Harandi A, Soleymani A, et al. Evaluation of the accuracy of two apex locators in endodontic treatment and retreatments: an ex vivo study. Caspian J Dent Res 2016;5:21-8.

[14] Bhat KV, Shetty P, Anandakrishna L. A comparative evaluation of accuracy of new-generation electronic apex locator with conventional radiography to determine working length in primary teeth: an in vivo study. Int J Clin Pediatr Dent 2017;10(1):34-6. 
[15] Kuştarci A, Arslan D, Altunbaş D. In vitro comparison of working length determination using three different electronic apex locators. Dental Research Journal 2014;11(5):568-73.

[16] Kaufman AV, Katz A. Reliability of Root ZX apex locator texted by an in vitro model. J Endod 1993;19(4):201.

[17] Dandempally A, Muppa R, Duddu MK, et al. Formulating a regression equation for determination of working length in primary molars using apex locators: a clinical study. Eur Arch Paeditr Dent 2013;14(6):369-74.

[18] Kielbassa AM, Muller U, Munz I, et al. Clinical evaluation of the measuring accuracy of ROOT ZX in primary teeth. Oral Surg Oral Med Oral Pathol Oral Radiol Endod 2003;95(1):94-100.
[19] Oznurhan F, Unal M, Kapdan A, et al. Clinical evaluation of apex locator and radiography in primary teeth. Int J Paediatr Dent 2015;25(3):199-203.

[20] Elayouti A, Weiger R, Lost C. The ability of Root ZX apex locator to reduce the frequency of overestimated radiographic working length. J Endod 2002;28(2):116-9.

[21] Gordon MPJ, Chandler NP. Electronic apex locators. Int Endod J 2004;37(7):425-37.

[22] Ahmad IA, Pani SC. Accuracy of electronic apex locator in primary teeth: a meta-analysis. Int Endod J 2015;48(3):298-307. 